\title{
O tóxico e o futuro da juventude
}

\section{Ovidio Gouveia da Cunha*}

O uso do tóxico pelos civilizados tem sido uma constante através dos tempos. Mas já o homem pré-histórico consumia entorpecentes. Os "Xamaus" do paleolítico entravam em transe pela aspiração da fumaça resultante da combustão de certos cogumelos. Os índios da meseta mexicana usam o tóxico de um cactus que, segundo eles, permite ao indivíduo transpor o espaço tempo e chegar a um estado de quase euforia metafísica. E se sabe também que a espansão árabe no norte da África foi muito influenciada pelo haxixe ou a diamba, isto é, a nossa conhecid íssima maconha, essa ervazinha bissexuada, cultivada em latinhas nos barracos das fa. velas.

A preocupação inicial dos sociólogos quanto ao tóxico no nosso país seria justamente a maconha. Mas, além da sociológica, existem outras implicaçōes: a filosófica, a política e, no mesmo ponto de vista sociológico, há que considerar-se a maconha em relaçăo à estratificação social. $\mathrm{Na}$ alta classe média e na classe média, a maconha é um flagelo, sintoma de que algo muito grave se passa no fundo da sociedade.

Entretanto, nos mocambos, nas favelas, e mesmo entre os escravos do Brasil imperial, a maconha não representa um sentido sociológico idêntico ao que hoje significa. E também o fumo de charuto pelo índio da América Central não constituía um problema social, da mesma forma que igualmente não era para o tupinambá viciado no charuto de folha de tabaco mal-curtido e no cauim, a cachaça de macaxeira com que fazia suas libaçoes depois dos festins comunais. Nesses estágios do uso do tóxico nāo se vê maiores conseqüências. Mas sabe-se hoje, através da imprensa e da sequeencia de fatos que chegam ao conhecimento público, que há conexão entre a toxicomania, a criminalidade $e$ as perversōes sexuais. E igualmente é ineludivel que o erotis. mo propagado através de revistas, filmes e exposiçoes se li. ga também à difusão do tóxico.

Esse é um fenômeno do nosso tempo. E, conforme os estudiosos, haveria uma motivação política no fundo desse problema: a Rússia e a China são as grandes fabricantes de matéria prima para essa epidemia ou pandemia de entorpecentes; e o maoismo teria estimulado o vício do tóxico no Ocidente para enfraquecer a sua juventude.

Não se deve, entretanto, escamotear a validade do argumento de que o vício do tóxico hoje caracteriza-se mais pela cocaína e esta é produzida na Bolívia de onde sai por dois corredores: Corumbá - Santos e Corumbá - Cuzco - Lima
* Departamento de Ciências Sociais da UFF, Niterói-RJ. 
- Bogotá - América Central - Miami, influenciando esferas alt íssimas da sociedade norte-americana. Por conseguinte, o ópio, no passado, o entorpecente da China, tem hoje menos expressão, enquanto a cocaína é de uso mais extenso, havendo, no entanto, também o ácido-lisérgico, que influi no neo-córtex, nas células gigantes piramidais, produzindo o fenômeno do eitetismo psíquico, isto é, uma exacerbação das imagens. Tomado em doses farmacêuticas homeopáticas, diga-se assim, esse ácido é preferido pelos pintores, compositores, e atores, para se tornarem mais sofisticados. É uma forma de excitação cerebral.

Considerando-se esse fato, agora é possivel a análise sociológica. É comum, nas obras de ciências sociais, encuntrar-se afirmação de que a toxicomania ou pandemia de tóxico na mocidade é conseqüente da guerra. Mas tivemos dois grandes conflitos armados na Europa, e o de 1939-1945 foi precedido da Guerra Civil Espanhola, que matou um milhão e meio de espanhóis, desorganizou a vida civil da Espanha, subverteu a própria família, criou o problema do menor carente e custou ao país ibérico mais de vinte anos para recuperar-se. Entretanto não consta que, ao término dessa guerra, houvesse ocorrido na Espanha uma epidemia de tóxico, nem tampouco onda de erotismo. E aquela foi uma guerra cruel, e as testemunhas oculares se horrorizaram ante a barbárie, as tempestades de violência, as atrocidades praticadas principalmente contra o clero espanhol.

E quanto ao primeiro conflito mundial, cessadas as hostilidades após o Armistício de 1918, não surge a toxicomania, depois que a França sacrificou três milhðes da fina flor da sua juventude, no Marne, na Flandres, nos campos do Norte, nas campanhas e batalhas como a de Verdun que, durante sete meses, eliminou um milhão e meio de jovens dos dois lados combatentes.

No entanto, o francês sempre gostou de um tóxico: o absinto. Verlaine, o grande poeta simbolista, e o próprio Beaudelaire consumiam o absinto, um perfumado refresco como o de hortelã que, tomado com gelo, é delicioso e produz um efeito curioso: um calor e um estado momentâneo de euforia sem embriaguês. É verdade que o Pernot (absinto) chegou a ser proibido pelo Gabinete francês. Mas essa foi uma medida transitória e sem maiores conseqüencias sociais.

Sobre esse velho hábito não se superpôs nenhuma invasão de toxicomania ou pornografia na França. Na literatura erótica, realmente, aparece um livro: "La Garçonne", um grande sucesso, mas lido às escondidas e sem nenhum efeito social.

Mas esquecem-se desses precedentes, e se diz que a toxicomania nos Estados Unidos é conseqüência do Vietnan. $O$ fato é que a Grande Guerra terminada com o Armistício de 1918 não gerou toxicomania. Ao contrário, causou foi um movimento de art-nouveau, a arte moderna dos modernos 
pintores, as novas correntes artísticas como o Dadaísmo e o Simbolismo que aos mil novecentos e vinte e dois repercutem no Brasil, na Semana de Arte Moderna, a qual, por paradoxo, em sua própria rebeldia contra a dominação cultural estrangeira, era ainda influenciada pelo movimento surgido no Norte da França.

E, portanto, falso que a mocidade norte-americana tenha sido levada ao tóxico por influência da guerra no Sudoesteasiático.

A toxicomania surge na Europa com o movimento "hippie". E justamente na Suécia, neutra na guerra de 1939. 1945. Depois a avalancha invade a Inglaterra. E, em seguida; a Dinamarca e a Alemanha Ocidental, tomando conta de metade da juventude européia. Não consegue atingir, todavia, Portugal, Espanha e Itália; e a própria França só muito relativamente foi contaminada.

Esse fenômeno vai ser explicado por um caldo de cultura: o Poder Jovem. E que o constitui? A massa emergente da sociedade européia, o setor da população de 0 a 20 anos de idade, após uma comoção social, liberta de antigas tradições, fizera a sua própria sociedade e o seu próprio mundo - o mundo do "hippie". E por ser o do jovem, é o universo da contestação. Na primeira adolescência o jovem tem a fase de transição. Está num momento de penumbra social, quer afirmar-se e, para isso, nega tudo que está ao seu redor. Não sentindo ou não vivendo o fenômeno do herói nem do anti-herói, não possuindo modelos éticos para afirmar-se, o jovem começa a apoiar-se em outro jovem. E se criou o movimento "hippie", que se apresenta com as seguintes características: psicologia transacional (liberdade sexual), experiência sensorial de coisas novas como aspirar cocaína e fumar, pela curiosidade de experimentar sensações inéditas.

Aconteceu, assim, um fenômeno de natureza epidêmica que encontrou seu filosófo: Marcuse. A mocidade está sem liderança, sem herói nem anti-herói. E o lider encontrado foi um velho (Marcuse, à época, deveria andar pelos oitenta anos).

Havia ao menos originalidade no pensamento marcusiano? A verdade é que não havia nenhuma. Marcuse consegue ser apenas a reedição alemã da velha filosofia dos cínicos de Atenas, os liderados de Diogenes, " o cínico" (não confundir com Diogenes Laercio), aquele que vivia em um tonel e, pregando a liberdade absoluta, convidava um casal jovem a ter relações sexuais na praça pública em meio a um círculo de aplaudidores e que recomendava também o nudismo. Interrogado por Alexandre sobre o que era a verdade, Diogenes respondeu: "fazendo sombra à entrada do meu tonel, tirais-me a única verdade, a que não me poderia dar: a luz do sol". Perguntado como ele entendia ser o homem definido por Platão, contestou: "o homem de Platão é um bípede implume". De modo que Diogenes era um "cínico". E a pa- 
lavra vem de "cinis", cão em grego, porque esse animal realiza publicamente o ato sexual, o que em geral não acontece com outros mamíferos. O gato, por exemplo, é muito mais pudico que o homem e o macaco. E o cão sendo, assim, um "cínico", em seu comportamento, apresenta uma espécie animal de analogia com a filosofia "cínica".

Entretanto, religiðes como a.Hare Krisna não se opø̃em ao tóxico. E a ofensiva da horda "hippie" na Europa identifica-se, também, por sua mania perambulatória: os jovens motoqueiros saíram estrada afora e atingiram a Ásia, o Tibet e o Nepal. E aí entregaram-se francamente às drogas.

Nas religiões asiáticas não existe grande condenação à usança de entorpecentes. Ao contrário, há tolerância em relação ao tóxico e se observa mesmo certa conotação entre as drogas e as religiões, principalmente no que diz respeito a algumas seitas bramânicas.

Todavia, é preciso excluir o zen-budismo, a espécie de budismo da China dos Imperadores que, realmente, aparece como uma religião séria, auto-sotérica, de grande espiritualidade, não apresentando nenhum perigo. Aliás, essa é a denominação de budismo que, trazida por seus monges, começa a penetrar em São Paulo.

Existem, entretanto, outras seitas que precisam ser muito bem estudadas, sobretudo uma determinada, muito perigosa e existente na América do Norte.

É muito natural que cultos como esses proliferem em épocas de grande tragédia social como a contemporânea um período histórico "sui generis".

O quadro preliminar do problema está mais ou menos armado. O jovem é contestador. Quer afirmar-se. Rompeu com o passado. Nada tem a oferecer para substituir a cultura pretérita. Vai abrir o seu baú e dele retirar o que existe de pior.

Os anacoretas de São Bento surgem em um tempo análogo ao nosso, de profunda desintegração social. Fundando o anacoretismo, São Bento vai para o campo. Medita e ora. E, longe da cidade, encontra outros jovens que também fugiam da sociedade do seu tempo, em busca daquilo que os antropólogos hoje chamam de "sociedades alternativas". Esses jovens anacoretas foram se reunindo e formando o cenóbio. A ordem de São Bento - a mais antiga Ordem de meditação do Cristianismo -, do ponto de vista sociológico e se abstraindo da natureza sagrada da Ordem Beneditina, nasce de um fenômeno de psicologia social comparável ao fenômeno "hippie" de nossos dias.

Agora, defina-se com o diagnóstico certo o "hippie", caldo de cultura da toxicomania dos jovens. Esta não é fenômeno político, nem existe hoje de forma igual a do passado, e se apresenta com um sentido de pandemia social. Por quê? Porque se caracteriza por uma ruptura na sociedade moderna. A sociedade tradicional construída sobre valores como a 
família monogâmica nuclear, a propriedade privada, a autoridade vertical hierarquizada, as concepções religiosas do catolicismo, do calvinismo, e do protestantismo em geral, enfim, todo o complexo da cultura ocidental vai se questionando e recebe uma espécie de implosão no fenômeno da toxicomania, um acontecimento psicológico de conotações até filosóficas. Porque, com efeito, para muitos escritores alemães, o toxicômano interpreta seu apelo ao tóxico com forma de suicídio lenta e insofrida.

Não há perspectiva nem horizontes para os jovens modernos. Na Europa, assim como nos Estados Unidos, o moço defronta-se com questões terríveis. De um lado, imediatamente, o problema do desemprego, e, de outro, vê no futuro o horror do fantasma apocalíptico da guerra nuclear. $\mathrm{E}$ surge um paradoxo: quanto mais culto, mais o jovem está vulnerável a sucumbir ante a tentação do tóxico. E é lamentável que a civilização agora existente na Europa e nos Estados Unidos não tenha condiçðes, em sua estrutura sócio-econômica, para absorver os jovens na sociedade aberta enquanto, ao mesmo tempo, lhes dá de graça uma sofisticada cul tura universitária de filosofia, psicologia, ciências sociais, e comunicação.

Essa juventude adquiriu um cabedal de conhecimentos. Mas é cética, descrente e qüestiona os filósofos gregos. $\mathrm{E}$ quanto maior é a sua cultura, maior é o seu desencanto interior. Parte então em busca de uma forma de suicídio lento. E se entrega ao sensualismo e aos prazeres. Porque sabe que tem de viver o presente, pois o futuro não existe. E se destrói lentamente na lama do tóxico.

Em evidente contraste a toda essa angústia ocidental, no outro lado do mundo, uma civilização como a da cultura japonesa, com seus mais de cem milhðes de homens, não pensa em drogas. $\mathrm{O}$ xintoísmo, sua religião, autoriza e recomenda o suicídio.

Apesar dessa predisposição, é muito baixo o índice de suicídio naquele país do Extremo Oriente. No Império do Sol Nascente, o jovem não está alienado e, por isso mesmo, não existe epidemia de suicídio e nem o problema dos entorpecentes.

Pelas mesmas razões, o jovem também não se encontra desligado do pacto social na Península Ibérica, nem na Itália, nem na Rússia. E é explicável a não alienação da juventude naquelas naçסes: de alguma forma, a sociedade tradicional não sofreu rutura em nenhuma delas. Quanto à Rússia, pode-se dizer que é um país conservador. A despeito da tirania e da pressão sem precedentes históricos da desumana orweliana e brutal máquina do Estado totalitário, os valores morais do homem ain da resistem e estão de pé na União Soviética. Sem dúvida, há o alcoolismo no país dos tzares, mas sem similitude com o fenòmeno do tóxico. E uma imposição do clima, um vício que o governo procura combater. 
A noite de seis meses passa sobre a Rússia do Norte, a Finlândia, a Suécia e a Noruega. E é difícil avaliar a ação sobre o espírito humano de um tão prolongado período de trevas quando se contam as horas que faltam para novamente raiar o dia.

Em violento contraste com esse mundo de frio e escuridão, o nosso é um país de esplendor do sol - de luz e calor. Quando o teatrólogo do absưrdo - Ionesco - veio ao Brasil, falou de sua admiração por nossa terra, onde se sentia a vitalidade da existência biológica. E realmente, veja-se apenas um exemplo, ou antes, sinta-se a magnífica festa tropical da humanidade na praia brasileira.

Em um quadro como esse, a juventude não tem o direito de sentir-se deprimida. Poderá ir para o tóxico por dois fatores: ou por imitação, fator perigoso porque o homem é um animal imitador, ou pelo fenômeno de vingança contra os país, isto é, da vontade de se vingarem do estado de desintegração da família causado pela independência econômica da mulher que, ao trabalhar, troca seu papel social e transforma o lar em simples lugar de dormir.

A especulação imobiliária - é a dura verdade - transformou as megalópolis do nosso Rio de Janeiro em um monstro - o solo vertical. E não somente no Rio, onde Copacabana tem hoje a maior densidade demográfica do mundo, mas, igualmente, em Santos, ou na Praia da Boa Viagem, no Recife, assim como a Praia de Iracema, na Fortaleza, que se tornaram lugares com cubículos, simples dormitórios onde no espaço de $50,00 \mathrm{~m}^{2}$ coabitam mais de 30 pessoas.

Essa monstruosidade social resultou da falta de planejamento, um defeito dos nossos administradores. Mas na realidade existiram urbanistas como Agache, que a visão moderna do grande prefeito Prado Junior, escolhido pelo Presidente Washington Luiz para administrar o Distrito Federal, trouxe com recursos do seu próprio bolso para fazer, ao fim dos anos vinte, já demolido o Morro do Castelo, o Plano do Rio de Janeiro.

Uma cidade nos trópicos, o Rio precisa ter zonas de indústrias, de comércio e de residência. As praias devem ser amplas e não muito edificadas, mas transformadas em parques públicos. Os morros devem ser urbanizados, não com a conservação demagógica das favelas, mas com a sua eliminação e $o$ aproveitamento dos seus habitantes, recuperados através de amplo processo reeducativo e definitivamente absorvidos e integrados no complexo sócio-econômico de nossa urbe incomparável. Todo esse conjunto foi concebido por Agache, com a orientação sociológica do seu urbanismo.

No entanto, repetem-se hoje na Barra da Tijuca os mesmos erros de Copacabana, Ipanema e Leblon. E se repetem porque continua a existir a chamada especulação imobiliária.

Assim, é a forma de vida artificiosa, quer dizer, as más 
condiçðes de existência nas grandes cidades que levam o jovem brasileiro ao tóxico. Mas igualmente nas cidades do interior o tóxico começa a penetrar, ainda que com outros aspectos e pelas próprias vias de comunicação.

Em 1937 o autor visitou Lagoa de Baixo, sertão pernambucano. Entrou ali como se entrasse no Saara, mas de automóvel, com o secretário do Governador ao lado, garrafa térmica e gelo. Sob o intenso calor tudo fotografou para uma obra de geografia.

Lagoa de Baixo era apenas meia dúzia de casas. Nenhum hotel. A comida era carne de sol e farinha. Estava-se na boca do sertão. E se imagine como seria ainda mais para o interior.

Hoje a televisão mostra uma festa em Exú, nesse mesmo interior: jovens de calça "jeans" e tudo exatamente como qualquer cidade do sul do país. A única diferença seria um ou outro xaxado, a dança típica da região. A comunicação de levar a grande cidade para o interior.

A mesma rutura cultural na Europa, produzindo a pandemia de tóxico, pode também ter ocorrido no Brasil, levando os jovens do interior a receberem, de um lado, os benefícios da cidade grande e, de outro, os seus males e perigos: o tóxico, o assalto, a criminalidade.

Pensem-se que era o Guaporé (Rondônia), nos tempos de Rondon, que percorreu $40.000,00 \mathrm{~km}$ (o diâmetro da terra) plantando o telégrafo, explorando o Hinterland, pacificando os índios. Agora, Rondônia manda às convenções na capital cultural do país, suas delegações femininas, de diálogo moderno e opiniões brilhantes. Houve, portanto, uma mudança profunda. O Brasil vive um processo de expansão que pode trazer conseqüências tremendas e, entre essas, a derrota da juventude pelo tóxico. E tudo pode acontecer não por degradação interior, não porque a desesperança haja tomado conta dos espíritos, mas por um fenômeno de cultura reflexa, a imitação com o grande vetor desta pandemia, a televisão. Seriam o "rock", a guitarra elétrica, a discoteca, os causadores da excitação dos jovens, a qual somada a outras exacerbações o levaram ao tóxico?

Estranho é que, por outro lado, o jovem moderno não é um erótico, propenso ao paroxismo da sensualidade. É inegável que as gerações anteriores eram muito mais eróticas. Dançava-se abraçado, rosto a rosto. Hoje, nos bailes, todos se contorcem sozinhos numa estereotipia nervosa, com música infernal.

Outra negação do jovem é a da autoridade. Ele não a aceita como imposição, mas a respeita quando ela se impõe de forma natural. Assim, se um professor vai para a sala de aula conhecendo a matéria, o jovem o aceita sem importar-se se o mestre é titular ou contratado. Por outro lado, o moço é manipulado por um grupo pequeno que está ali com finalidades políticas e ideológicas e que, de um modo sutil, 
o envolve como massa de manobra, levando-o a reproduzir "slogans", e tornando-o um verdadeiro estereótipo social.

$\mathrm{Na}$ sua experiência de dez anos na Universidade Federal Fluminense, o autor viu os jovens irem para as aulas à vontade, sem a menor malícia. Se namoram, o fazem de maneira muito espontânea, sem a menor preocupação de esconder o namoro.

Certa vez surgiu um projeto vindo de Universidade inglesa. Propunha a implantação em nossa Universidade da psicologia transacional, isto é, de um conjunto de práticas nas quais os jovens poderiam agir livremente e até mesmo terem relações sexuais. É claro que uma reunião do departamento não tomou conhecimento dessa sugestão, motivo de riso e pilhéria. Mas a proposta inglesa existiu, era um convite à promiscuidade sexual e revelou tendência muito grave da sociedade moderna.

Como as ondas do mar, em seu ciclo eterno, a civilização vai e volta. Mas certos valores são constantes na vida civilizada. Ora a sociedade é repressiva, ora não. Nessa al ternativa de valores há a busca de felicidade, fundamentalmente a procura do prazer, uma satisfação psicológica, o encontro de uma filosofia existencial e o ajustamento econômico. É dentro desse quadro que o jovem clama hoje pela liberdade. Mas será preciso adverti-lo de que não é exatamente a liberdade o que ele procura, mas a segurança.

Onde, então, se encontra o dique para conter a grande inundação dos tóxicos? Há o reconhecimento geral de que o mundo está perturbado e envolvido em gravíssima crise de características muito específicas. E entre os componentes desse sofrimento universal os mais originais serão, talvez, de um lado, a ameaça de guerra nuclear e, de outro, a partida do homem no rumo do espaço cósmico.

A conquista espacial trará para a humanidade grandes perturbações no pensamento filosófico, tão profundas como a descoberta do heliocentrismo de Copémico, que desarmou a Idade Média de sua filosofia teocêntrica, católica, e propôs a filosofia antropocêntrica do Renascentismo.

Com a invasão das fronteiras cósmicas, o homem é levado a duvidar de que esteja sozinho no Universo. Não deve ser o rei de nada, uma vez que a sua Terra é apenas um grão de poeira flutuando na infinita imensidão do Cosmos.

E essa noção - ou esse sentimento - fará estremecer as concepções filosóficas, científicas e políticas da humanidade.

Ao lado dessa consciência de que o mundo está no limiar de uma nova era, se vê a ameaça da catástrofe sem precedentes do apocalipse atômico.

Como, então, deter-se no Brasil e na Europa o maremoto da toxicomania?

$\mathrm{O}$ autor é agnóstico, mas reconhece: uma formação religiosa dada com seriedade à juventude (o que não é fácil porque ela questiona a religião e, assim, seriam necessários pre- 
gadores de nível elevado, ao mesmo tempo que líderes religiosos de perfeita estrutura moral) poderá dar aos moços uma alternativa para ocupar o vazio de suas almas, ou antes, para deter-se o processo de desintegração do mundo subjetivo do jovem e, assim, recuperá-lo para a convivência com os outros setores da sociedade.

A mensagem de esperança será o alimento emocional capaz de libertar ou livrar o jovem do espectro da toxicomania. E ao lado dessa mensagem aparece nova perspectiva: o progresso da ciência médica garantirá ao jovem de vinte anos hoje uma vida de cem anos.

E não valerá à pena realizar essa possibilidade de existir? Reconciliado com o mundo através de uma experiência espiritual religiosa - talvez no melhor sentido da "vivência", como teria dito Ortega y Gasset - o jovem devolvido à alegria de viver poderá experimentar uma nova, longa, extraordinária e esplêndida aventura existencial, renascendo de suas próprias ruínas.

Essa será a única forma de conter-se a grande onda do tóxico - um mal terrível e capaz até de gerar a criminalida. de sem fins econômicos.

No Brasil, o crime tem causas econômicas. Mas na Europa a criminalidade do jovem tem tido origem na busca da emoção do perigo. Os mais espetaculares assaltos foram praticados por jovens de boa situação econômica, amparados por seus familiares. E, na Alemanha, as estatísticas mostraram um surpreendente fenômeno: o caminho do crime não era escolhido pelo desempregado. $O$ desrespeito à lei não resultava da fome, mas do vácuo na alma dos jovens ricos, perdidos no mundo, impelidos à violência - em última análise - à subversão dos valores - que constituem os próprios fundamentos da formação da cultura e da civilização do Ocidente. 